\title{
Spatial Effects in Willingness to Pay for Avoiding Nuclear Risks ${ }^{a}$
}

\author{
Yves Schneider $^{\mathrm{b}}$ and Peter Zweifel $^{\mathrm{c}}$
}

JEL-Classification: R3, L94, C9.

Keywords: citation, discrete choice experiment, liability insurance, nuclear accident, willingness to pay.

\section{Introduction}

The risks associated with nuclear power cause a great deal of debate in many countries. The two most prominent are accidents at the power plant and waste disposal. As to the first, economic theory predicts that marginal willingness to pay for reducing the financial consequences of a nuclear power plant accident $\left(M W P_{C}\right)$ depends on distance from plant. However, one needs to take into account that residential location is endogenous because individuals concerned about nuclear risks tend to locate farther away from nuclear power plants. Since there are many other factors that determine an individual's residential location, distance from plant is expected to have an effect only on those individuals' $M W P_{C}$ for whom nuclear risks are important. Moreover, locational choice is a costly alternative for reducing one's exposure to nuclear risks. Thus there will be positive willingness to pay (wtp) for reducing the exposure further even after an individual's choice of residential location. We find evidence that $M W P_{C}$ for individuals concerned about nuclear accident risks tends to increase with distance from plant whereas $M W P_{C}$ for individuals less concerned about nuclear accident risks tends to decrease with distance.

a We want to thank Michael Breuer, Patrick Eugster, Charles Holt, Harry Telser, Christian Wyss, participants at the ASTIN conference and at the annual meeting of the Swiss Society of Economics and Statistics, seminar participants at the Universities of Virginia and Zurich and at the Curtin Business School (Perth, Australia) for valuable comments. Financial support came from the Swiss Federal Office of Energy and the Swiss Institute of Technology. Yves Schneider acknowledges financial support by the Swiss National Science Foundation via grant PBZH1-117037. Any errors and omissions are ours.

b University of Lucerne and Polynomics, Baslerstrasse 44, 4600 Olten, Switzerland. Email: yves. schneider@polynomics.ch.

c Emeritus, Department of Economics, University of Zurich, Switzerland. Email: peter. zweifel@econ.uzh.ch. 
As to the second risk, distance from plant should not have an impact on wtp for having a solution to the waste disposal problem $\left(M W P_{W}\right)$. The reason is that even an individual residing far from plant may face the possibility of trucks with radiating materials to pass close by.

By choosing a location further away from nuclear power plants, individuals self-insure: They reduce their losses which are caused, for example, by radiation in case of a severe nuclear accident. EHrLich and Becker (1972) analyze the effect of the simultaneous availability of self-insurance and market insurance and conclude that both "technologies" are substitutes as long as the price of market insurance is independent of the amount of self-insurance. Since up to now it has not been possible for Swiss citizens to buy insurance against the financial consequences of nuclear risks, the only option available is self-insurance. In the absence of an insurance market, the optimal level of self-insurance increases with increased risk aversion (see e.g. Dionne and Eeckhoudt, 1985).

We conducted a discrete choice experiment that introduces a hypothetical market for insurance against nuclear risks. In SCHNEIDER and ZwEIFEL (2004) we estimated respondents' willingness to pay for increased insurance coverage against nuclear risks but did not take the spatial dimension of respondents' preferences into account. However, respondents evidently make their choices in our experiment after having set their optimal level of self-insurance through their residential choice. Although there is no need to account for strategic interaction between market insurance and self-insurance (KeLly and KLEFfner, 2003), it is necessary to account for self-insurance that has taken place prior to the experiment. Thus, estimated wtp for insurance coverage is expected to vary systematically with the degree of self-insurance, i.e. with respondents' distance from nuclear power plants in the present context.

There is a large body of empirical work estimating the effect of proximity to a source of disamenity on property values. The case of nuclear power plants was first studied by Nelson (1981) and Gamble and Downing (1982). In the wake of the 1979 incident at Three Mile Island, they find weak or even reversed distance effects, viz. higher property values in the vicinity of the plant. FolLand and Hough (2000) extend their focus beyond a single power plant, analyzing a panel data set of broad market areas across the United States. Their evidence points to a negative impact of nuclear power plants on land prices, with distance again having an ambiguous effect. Gawande and Jenkins-Smith (2001) find that being five miles away from a nuclear waste shipment route was associated with a 3 percent increase of average house value compared to property on the route.

Nuclear power is but one of many potential sources of disamenities. In their review, Gawande and Jenkins-Smith (2001) conclude that a wide range of 
disamenities such as Superfund sites and polluted water negatively influence the value of residential property. FARBER (1998) finds that the effect of distance from the source of the disamenity depends on the type of facility, community characteristics, and setting (rural or urban). Chemical refineries and nuclear power plants seem to have roughly comparable (positive) gradients, amounting to USD 200-300 per mile of distance (in 1993 dollars). Compared to other facilities, this is a rather small effect, as a proposed radioactive waste disposal site was associated with a gradient of USD 4,440 per mile. As Clark and Allison (1999) found in their study, the distance effect weakens over time, suggesting that relocation of individuals may replenish demand for property close to the source of the externality by those who believe to be little affected.

Turning to stated choice rather than market-based studies, SMITH and DesvOUSGES (1986) employ a contingent valuation study to analyze the impact of distance between respondents' homes and land based disposal sites for hazardous wastes on the subjective value of these homes. They obtain a positive distance gradient of USD 330-495 per mile. A study related to the present paper is by Riddel, Dwyer, and Shaw (2003), who estimate the effect of several planned nuclear waste transportation routes from power plants to the Yucca Mountain (Nevada) repository. They find evidence that perceived risk decreases with distance to the planned transportation route and that higher perceived risk results in a higher probability of moving away from the route.

Most existing studies rely on hedonic modeling, linking price data to a set of characteristics of real estate property. As Davis (2004) points out, the heterogeneity of individuals (with respect to income or preferences in general) contaminates housing price data. Furthermore, the cost of changing location, which constitutes the cost of this particular self-insurance technology, is arguably not trivial. Moreover, market prices also depend on supply which in turn is affected by zoning laws and building regulations. For these reasons, estimates of individual wtp derived from analyzing the compensating differentials contained in market data are potentially distorted and incomplete. Experimental evidence, while having its own drawbacks (see e.g. Diamond and Hausman, 1994), may thus complement information gleaned from market data.

The remainder of this paper is structured as follows. Section 2 describes the stated choice experiment that was applied to measure wtp of the Swiss population for reducing nuclear power externalities. The hypotheses to be tested are formulated in Section 3, while the econometric specification is presented in Section 4. Estimation results follow in Section 5, and concluding remarks are offered in Section 6. 


\section{The Discrete Choice Experiment}

Our discrete choice experiment (DCE) $)^{1}$ was conducted in 2001 and was designed to elicit individuals' wtp for reducing their financial exposure to two nuclear risks: accident at the plant and disposal of spent fuel.

In discrete choice experiments, respondents are confronted with hypothetical choice situations where they have to decide whether they prefer the status quo or some alternative product (which potentially differs in all product attributes). For each such choice set, respondents have to indicate their preferred choice, which requires them to trade off one set of attributes against the other, implicitly revealing their preferences regarding the different attributes.

Table 1: Levels of Attributes

\begin{tabular}{llll}
\hline Attribute & Levels (Coding) & Unit & Status quo \\
\hline PRICE & $0 ; 10 ; 30 ; 60(0 ; 10 ; 30 ; 60)$ & percent & 0 \\
BLACKOUTS & $2 ; 14(0 ; 1)$ & number/year & 0 \\
NOWASTE & $\begin{array}{l}\text { unresolved problems }(0) ; \\
\text { no unresolved problems }(1)\end{array}$ & 0 \\
\hline DAMAGE $^{a}$ & $0.1 ; 10 ; 100 ; 200(0.1 ; 10 ; 100 ; 200)$ & CHF bn. & 200 \\
COVERAGE $^{\text {Con }}$ & $1 ; 20 ; 50 ; 100(1 ; 20 ; 50 ; 100)$ & in percent of loss & 1 \\
\hline
\end{tabular}

a Values in USD bn.: 0.1; 10; 100; 200 (USD $1 \sim$ CHF 1 at 2010 exchange rates)

DCEs are applied in fields such as health economics, environmental economics, and industrial organization. For a recent overview of DCE in health economics see de Becker-Grob, Ryan, and Gerard (2010). In industrial organization DCEs are used to estimate price elasticities of demand (see IDA and Kuroda, e.g. 2006). In the present context, the DCE has individuals choose among different types of electricity. During the decision process, the attributes (among them price) of electricity are traded off against each other. Participants in the experiment are asked to pairwise evaluate several different electricity products by indicating their preferred choice (see Appendix A1 for an example). In a telephone survey preceding the main survey, the following five product attributes

1 Bishop and Heberlein (1979) followed by Hanemann (1984) introduced discrete choice contingent valuation experiments to environmental economics. For an overview see Louviere, Hensher, and Swait (2000). 
emerged as the most important (see Table 2): average price per kwh (PRICE), reliability defined as low frequency of blackouts (вLAскоUт), secure and sustainable waste disposal (NOWASTE), size of area exposed to hazard (DAMAGE), and financial compensation of victims in case of an accident (COVERAGE). Because this study is concerned with insurance against financial risks of a nuclear accident, DAMAGE was defined as billions of CHF at risk rather than area exposed to hazard while reducing the financial consequences of nuclear power plant accidents was framed in terms of an increase of mandatory liability insurance carried by nuclear plant operators. ${ }^{2}$

Table 2 shows the different levels of each attribute. PRICE was framed as a $0 \%$, $10 \%, 30 \%$, or $60 \%$ increase of the respondents' annual electricity bill. Because respondents also provided information on their annual electricity bill, we converted these relative price increases into absolute price increases expressed in CHF and termed this new variable outLAY.

The attribute BLACKOUT served as a proxy for service quality and was coded binary: The electricity product is either associated with a low incidence of blackouts (2 per year, BLACKOUT $=0$ ) or a high incidence of blackouts (14 per year, BLACKOUT $=1)$.

The waste disposal problem was incorporated through the binary attribute NOWASTE. It can either attain the level "unresolved problems with waste disposal" (NOWASTE $=0$ ), which corresponds to the status quo, or the hypothetical level "no unresolved problems with waste disposal" (NOWASTE $=1$ ). The attribute was described as follows, "... Disposal of waste occasions problems and risks of variable magnitude. This holds in particular for nuclear waste, where these problems are not resolved yet." Respondents were instructed to assume that whenever a type of power was associated with "no unresolved problems with waste disposal" waste disposal was indeed solved and no longer an issue.

The attributes DAMAGE and COVERAGE described the possible damage a power plant can cause and what part of it was covered by a liability insurance. DAMAGE was framed in CHF billions and CoveraGe as the percentage of that damage covered by insurance.

Note that the DCE did not include the probability of an accident at the power plant but treated it as constant. The survey provided information on experts' estimate of accident probabilities and asked respondents to indicate their own subjective belief about the accident probability relative to the experts estimate. This information was used to categorize the respondents into "pessimistic" respondents

2 At the time of the DCE, operators were obliged to insure for CHF 1.8 billion (bn.), which amounts to approx. USD $1.8 \mathrm{bn}$. [USD $1 \approx \mathrm{CHF} 1$ at 2010 exchange rates]. 
if they considered an accident to be more than ten times more probable than experts do (see Table 2).

The various levels of the five attributes result in a total of $256(=4 \cdot 2 \cdot 2 \cdot 4 \cdot 4)$ possible scenarios. Out of these 256 potential attribute combinations we choose a D-optimal design that allows us to estimate all linear, quadratic, and interaction effects. ${ }^{3}$ A D-optimal design maximizes the determinant of the Fisher information matrix for linear models. This does generally not result in an optimal design for non-linear models like ours. However, an optimal design for nonlinear models depends on the value of the estimated coefficients and is thus not easily determined ex ante before estimating the model. One could employ an iterative procedure in which the design is updated based on results from a first round of estimates. The updated design would then be used to generate a new set of estimates, and so on. Unfortunately we were not able to implement such a considerably more costly survey procedure. We chose a D-"optimal" design which, although not optimal for our non-linear model, is more robust than the truly optimal design which is sensitive to the assumed parameter estimates. For a discussion of issues in the design of discrete choice experiments see, for example, Louviere, Pihlens, and Carson (2010).

The questionnaire for the main survey was divided in three parts: warm-up questions, the actual choice experiment, and socioeconomic information. In the first part, data on monthly electricity outlay, attitudes towards nuclear energy, and the importance of choice between different types of electricity was collected. Respondents then had to read a description of the risks of nuclear and hydro power plants. Emphasis was put on possible worst-case scenarios and their financial consequences. Respondents were also told that nuclear power plants were already mandated to have liability insurance but that coverage fell far short of possible financial loss in case of a major accident. A more detailed description of the questionnaire can be found in SCHNEIDER and ZwEIFEL (2004) and is available from the authors.

The second part of the questionnaire consisted of the actual DCE. Respondents were confronted with 14 different choice situations where they had to decide whether they preferred a proposed type of power to the status quo. They could always opt out by stating "cannot decide" (see Appendix A1 for an example). In the third and last part of the questionnaire, standard socioeconomic data was collected. Table 2 summarizes the socioeconomic data used in the estimation. Specifically, distance from the nearest nuclear power plant (DIST) was calculated using zip codes provided by respondents. PESs $=1$ obtains if on a visual analog

3 We used the program Gosset by Hardin and SLOANE (1991-2003) to find the optimal design. 
Table 2: Sample Description of Explanatory Variables

\begin{tabular}{llccc}
\hline & Description & Mean & Median & Std. dev. \\
\hline DIST & $\begin{array}{l}\text { distance in kilometers from respondent's residence } \\
\text { to nearest nuclear power plant. }\end{array}$ & 45 & 36 & 30 \\
PESS & $\begin{array}{l}\text { = } 1 \text { if respondent considered a nuclear accident at } \\
\text { least ten times more probable than experts. }\end{array}$ & 0.59 & 1 & 0.49 \\
OPPONENT & $\begin{array}{l}\text { = } 1 \text { if respondent said to be against nuclear energy } \\
\text { even if there was no waste disposal problem. }\end{array}$ & 0.21 & 0 & 0.41 \\
SEXM & $=1$ if respondent is male. & 0.52 & 1 & 0.5 \\
INCOME & $\begin{array}{l}\text { yearly income in CHF. Seven income categories } \\
\text { were used in the questionnaire. 44 percent did }\end{array}$ & 73,480 & 60,000 & 35,400 \\
& not reveal their income. & & & \\
\hline inc_missg & $=1$ if income missing & 0.44 & 0 & 0.5 \\
\hline
\end{tabular}

scale, respondents marked their estimated accident probability at least one order of magnitude higher than experts. This variable serves as an indicator for the respondent's concern about nuclear risks.

Moreover, respondents were asked to indicate their income. Since more than 40 percent of respondents refused to indicate their income, restricting the sample to individuals with information on income had to be avoided. The solution retained is to equate missing values to zero (INCOME $=0$ ) while creating a dummy variable INC_MISSG that takes on the value of one if income information is not available. ${ }^{4}$

Face-to-face interviews were performed with randomly drawn respondents in the German-speaking part of Switzerland. In total, 391 persons were interviewed. Each respondent evaluated 14 choice scenarios, resulting in 5,474 recorded decisions. After excluding inconsistent choices (we added one dominated alternative to check for consistency of responses), "cannot decide" answers, and missing values, a total of 4,613 observations were retained.

\section{Hypotheses to Be Tested}

We focus on the effect of distance from nuclear power plants on marginal willingness to pay for (i) increased insurance coverage against accidents at nuclear power plants and (ii) for solving the nuclear waste disposal problem.

4 This procedure assumes that information on income is missing at random. 
(i) When deciding about the choices presented to them in the DCE, participants arguably take the distance from their residential location to the next nuclear power plant into account. If located far away, they are less affected by an accident. This argument assumes that respondents' residential location choice, which took place prior to the experiment, was independent of the presence of a nuclear power plant. Because the last nuclear power plant in Switzerland was built in 1984, it seems quite implausible that residential location occurred independently of decisions concerning distance to nuclear power plants. Assuming that respondents differ with respect to their preferences for (against) nuclear power (e.g. because of heterogeneous subjective accident probabilities), the more skeptical types should be found farther away from the plant. Therefore, respondents located farther away from the plant have a higher disutility from nuclear risk and may well be willing to pay more for additional insurance coverage against operational risk than those located in its vicinity.

However, by locating farther away these types reduced their exposure to the accident risk. The two counteracting effects of sorting (the skeptical types select locations far away) and self-insurance (being farther away reduces exposure) generate an inverted U-shape relationship of wtp for additional insurance coverage (denoted by $M W P_{C}$ ) and distance from the plant: Near the plant, $M W P_{C}$ values are low and increase with distance because the more concerned people live farther away (selection effect dominates). Beyond a certain distance, $M W P_{C}$ values start to decrease because the consequences of an accident at the plant become less important (the self-insurance effect dominates).

Nuclear risk is but one of many factors governing the choice of residential location. Employment opportunities, proximity to the family, recreational considerations are some of the factors affecting choice of one's residence. Hence, there is a significant cost associated with relocating, and sorting with respect to operational risk is expected to be less than perfect. However, the stronger a person's attitude towards nuclear risk, the greater is the weight of this risk in his or her decisions. Only persons with a strong negative attitude, high perceived risk or marked risk aversion are expected to rank operational risks high enough to make the sorting effect measurable in the available data.

Three indicators for respondents' attitude towards nuclear power plant are used in the estimation, (1) whether they state to be opposed to nuclear energy in principle (OPPONENT), (2) whether they perceive nuclear accidents to be much more likely than experts' best estimates (PESS), and (3) male sex (SEXM). The last indicator is based on several studies. Hartog, Ferrer-I Carbonell, and Jonker (2002) analyze the influence of individual characteristics on risk aversion and find survey evidence that men are less risk-averse than women. Nielsen et al. 
(2003) conclude that men have a lower perception of risk than women. Therefore, SEXM is predicted to display a negative relationship with $M W P_{C}$.

In Section 5 we show that women do indeed have significantly higher MWP for increased insurance coverage than men. However, their wtp monotonically decreases with distance from the plant as opposed to men's wtp. This points to another possible effect of gender on wtp. Because households rather than individuals choose their residential location, the intra-household decision process affects the degree of sorting. Suppose that on average the main breadwinners' preferences are reflected in a household's decision concerning place of residence. In this case, only the main breadwinner's $M W P_{C}$ is expected to increase with distance, while the other household members' (who did not sort) $M W P_{C}$ should be decreasing with distance. If the main breadwinners are predominantly men, then it is expected that they are more strongly spatially sorted than women.

(ii) Unlike the case of operational risks, individuals who fear the risk from nuclear waste transport or disposal gain little from putting more distance between their residence and a nuclear power plant. ${ }^{6}$ Therefore, DIST should not be a relevant predictor of wtp for solving the problem of nuclear waste $\left(M W P_{W}\right)$. This statement needs to be qualified in the following way. Shipping of radioactive waste and spent fuel necessarily originates at plants from where they are directed to the future national disposal sites (at present, the destinations are Le Hague in France and Sellafield in Great Britain). This implies that there is and will be an increased exposure to the risk of nuclear waste in the vicinity of the plant. For most values of DIST, however, the effect of distance on $M W P_{W}$ is expected to be zero.

The preceding arguments may be summed up in the following predictions:

1. Marginal wtp for higher liability insurance coverage $\left(M W P_{C}\right)$ may decrease or increase with distance from the nearest nuclear plant, depending on whether the direct risk effect of distance or the indirect sorting effect prevails. If the sorting effect prevails, $M W P_{C}$ is expected to increase with distance from the plant.

5 Until recently, men had the legal authority in Switzerland to decide about the residential location of a household.

6 Although a waste disposal site has not yet been designated in Switzerland, geological considerations make it unlikely for a future waste disposal site to be near the six existing plants (which are all located on rivers). 
2. By controlling for respondents' attitude and gender, and hence the sorting effect, $M W P_{C}$ is predicted to be a negative function of distance to plant.

3. Wtp for solving the waste (and hence transportation) problem $\left(M W P_{W}\right)$ is predicted not to depend on distance, except in the immediate vicinity of the plant.

4. Ceteris paribus, increasing values of $M W P_{C}$ and $M W P_{W}$ are expected with higher income since the marginal utility loss due to the increase in the price of electricity caused by stepping up liability insurance requirements should be decreasing in income.

\section{Econometric Specification}

Let an individual be confronted with a discrete choice, e.g. whether to buy a certain product or not. Given this choice, individuals maximize their (expected) utility with respect to their budget constraints, obtaining certain utility values. These values define an indirect utility function conditional on the alternative selected. It depends on individuals' characteristics, their incomes, on the particular attributes of the alternative (including price) as well as on various unobservable effects, which are assumed to be random.

In the present experiment, respondents were confronted with 14 binary choice situations, involving the status quo and an alternative. The dependent variable $y_{i}$ equals one if respondents chose the alternative and zero if they stayed with the status quo. Respondent $i$ 's expected indirect utility of the alternative in choice situation $j$ is denoted by $V_{i j}$; the one of the status quo, by $V_{m j}$. Respondents therefore chose the alternative $\left(y_{i}=1\right)$ if $V_{i j}-V_{i m} \geq 0$. The posited utility function reads

$$
\begin{aligned}
& V_{i j}=\beta_{0}+\beta_{1} \cdot \operatorname{COVERAGE}_{j}+\beta_{2} \cdot \text { NOWASTE }_{j} \\
& +\beta_{3} \cdot \text { BLACKOUT }_{j}+\beta_{4} \cdot \text { DAMAGE }_{j}+\beta_{5} \cdot \text {.UTLAY }_{j} \\
& +\beta_{6} \cdot \text { OUTLAY }_{j}^{2}+\beta_{7} \cdot \text { DIST }_{i} \cdot \text { NOWASTE }_{j} \\
& +\beta_{8} \cdot \operatorname{DIST}_{i}^{2} \cdot \operatorname{NOWASTE}_{j}+\beta_{9} \cdot \operatorname{DIST}_{i} \cdot \operatorname{DAMAGE}_{j} \\
& +\beta_{10} \cdot \operatorname{DIST}_{i}^{2} \cdot \operatorname{DAMAGE}_{j}+\beta_{11} \cdot \operatorname{DIST}_{i} \cdot \operatorname{COVERAGE}_{j} \\
& +\beta_{12} \cdot \operatorname{DIST}_{i}^{2} \cdot \operatorname{COVIERAGE}_{j}+\ldots \\
& +\beta_{25} \cdot \text { INCOME }_{i} \cdot \text { OUTLAY }_{j}+\beta_{26} \cdot \text { INC_MISSG }_{i} \cdot \text { OUTLAY }_{j}+\epsilon_{i j} \cdot
\end{aligned}
$$

The status quo remains the same for each individual during the experiment, hence for each individual $i$ the status quo utility $V_{i m}$ remains constant. Because only the 
utility difference $V_{i j}-V_{i m}$ determines choice, socioeconomic variables, that do not influence individuals' valuation of the status quo and the alternative product, cancel out. Put differently, unless socioeconomic variables are interacted with product attributes, they drop out of the equation. Therefore our estimated utility function contains various interaction terms between socioeconomic variables and product attributes in order to control for differences across socioeconomic groups.

A second consequence of the constant status quo utility $V_{i m}$ is that the error term $\epsilon_{i m}$ in the utility function for the status quo does not change either. This gives rise to an individual-specific error term $\mu_{i} \equiv \epsilon_{i m}$. Because only differences $V_{i j}-V_{i m}$ are relevant for an individual's decision, the error term of the estimated function is given by $\mu_{i}-\epsilon_{i j}$, calling for a random effects specification. ${ }^{7}$

The estimated utility function $\hat{V}(Z)$, with $Z$ being the vector of socioeconomic variables and product characteristics, permits to calculate marginal wtp for the different product attributes. It is defined as the marginal utility of the attribute divided by the marginal utility of income,

$$
M W P_{C}(\operatorname{Coverage} ; Z):=\frac{\partial \hat{V}(\operatorname{coverage} ; Z) / \partial \text { COVERAGE }}{\partial \hat{V}(\text { COVERAGE } ; Z) / \partial \text { OUTLAY }} .
$$

In the case of wtp for solving the nuclear waste problem, one has

$$
M W P_{W}(Z):=\frac{\hat{V}(\text { NOWASTE }=1 ; Z)-\hat{V}(\text { NOWASTE }=0 ; Z)}{\partial \hat{V}(Z) / \partial \text { OUTLAY }} .
$$

Willingness to pay values reported are in USD per year. Note that INCOME ${ }_{i} \cdot \mathrm{OUTLAY}_{j}$ and OUTLAY $_{j}^{2}$ permit marginal utility of income to vary with income.

\section{Results}

Estimation results are displayed in Table 3. All coefficients of product attributes (COVERAGE, NOWASTE, BLACKout, OUtLay, OUTLAY ${ }^{2}$ ) with the exception of DAMAGE show the expected sign and are highly significant, indicating that respondents were (on average) willing to make tradeoffs among the different attributes. Furthermore, the relative magnitudes of marginal utilities associated with product attributes are intuitively plausible, and they are quite in line with

7 A similar random effects probit specification is also used, e.g., in TELSER and Zweifel (2002) as well as Gyrd-Hansen and SLOthuus (2002). 
Table 3: Random Effects Prohibit Estimation Results.

The Dependent Variable Is the Probability of Accepting the Alternative Type of Power.

\begin{tabular}{|c|c|c|}
\hline & Coeff. & s.e. \\
\hline CONSTANT & 0.62489 & $0.09024^{* * *}$ \\
\hline COVERAGE & 0.02053 & $0.00424^{* * *}$ \\
\hline NOWASTE & 0.35806 & $0.17971^{* *}$ \\
\hline BLACKOUT & -0.35731 & $0.04953^{* * *}$ \\
\hline DAMAGE & -0.00034 & 0.00087 \\
\hline OUTLAY & -0.00339 & $0.00029^{* * *}$ \\
\hline OUTLAY $^{2}$ & $1.17 \cdot 10^{-7}$ & $1.11 \cdot 10^{-8 * * *}$ \\
\hline DIST $\cdot$ NOWASTE & 0.00556 & 0.00637 \\
\hline DIST $^{2} \cdot$ NOWASTE & $-3.20 \cdot 10^{-5}$ & $5.08 \cdot 10^{-5}$ \\
\hline DIST·DAMAGE & $-2.95 \cdot 10^{-5}$ & $3.58 \cdot 10^{-5}$ \\
\hline DIST $^{2} \cdot$ DAMAGE & $3.80 \cdot 10^{-8}$ & $2.95 \cdot 10^{-7}$ \\
\hline DIST.COVERAGE & $-5.39 \cdot 10^{-4}$ & $1.74 \cdot 10^{-4 * * *}$ \\
\hline DIST $^{2} \cdot$ COVERAGE & $3.35 \cdot 10^{-6}$ & $1.43 \cdot 10^{-6 * *}$ \\
\hline SEXM·NOWASTE & -0.18718 & $0.09561^{* *}$ \\
\hline SEXM $\cdot$ COVERAGE & -0.01489 & $0.00426^{* * *}$ \\
\hline DIST $\cdot S E X M \cdot C O V$ & $4.24 \cdot 10^{-4}$ & $1.77 \cdot 10^{-4 * *}$ \\
\hline $\mathrm{DIST}^{2} \cdot \mathrm{SEXM}^{\prime} \cdot \mathrm{COV}$ & $-2.11 \cdot 10^{-6}$ & $1.47 \cdot 10^{-6}$ \\
\hline PESS $\cdot$ NOWASTE & 0.09246 & 0.09762 \\
\hline PESS COVERAGE & -0.01148 & $0.00451^{* *}$ \\
\hline DIST $\cdot$ PESS $\cdot \mathrm{COV}$ & $4.04 \cdot 10^{-4}$ & $1.86 \cdot 10^{-4 * *}$ \\
\hline DIST $^{2} \cdot$ PESS $\cdot \mathrm{COV}$ & $-2.24 \cdot 10^{-6}$ & $1.54 \cdot 10^{-6}$ \\
\hline OPPONENT·NOWASTE & 0.33556 & $0.12145^{* * *}$ \\
\hline OPPONENT $\cdot$ COVERAGE & 0.00194 & 0.00528 \\
\hline $\mathrm{DIST} \cdot \mathrm{OPP} \cdot \mathrm{COV}$ & $-1.45 \cdot 10^{-5}$ & $2.11 \cdot 10^{-4}$ \\
\hline $\mathrm{DIST}^{2} \cdot \mathrm{OPP} \cdot \mathrm{COV}$ & $-4.02 \cdot 10^{-7}$ & $1.64 \cdot 10^{-6}$ \\
\hline INCOME·OUTLAY & $8.16 \cdot 10^{-9}$ & $2.81 \cdot 10^{-9 * * *}$ \\
\hline INC_MISSG·OUTLAY & $6.94 \cdot 10^{-4}$ & $3.15 \cdot 10^{-4 * *}$ \\
\hline $\ln \sigma_{u}^{2}$ & 0.10630 & 0.11006 \\
\hline$\sigma_{u}$ & 1.05459 & 0.05803 \\
\hline$\rho$ & 0.52655 & 0.02744 \\
\hline
\end{tabular}

Notes: $\mathrm{N}=4,613 ; 376$ respondents; $\log L=-2196.79 ; L_{0}=-2596.96 .{ }^{* * *},{ }^{* *},{ }^{*}$ significant at the $1,5,10$ percent level. 
Schneider and Zweifel (2004). Note that Coverage measures the increase in insurance coverage in percentage points, whereas NOWASTE is an all-or-nothing variable indicating whether or not there are any problems regarding nuclear waste.

Respondents are not only concerned about the risks associated with nuclear energy (COVERAGE, NOWASTE), but also about the frequency of power outages (вцACKOUT). Interestingly, respondents value a low frequency of power outages ( 2 instead of 14 per year) by the same amount as solving the waste disposal problem in that both variables have a coefficient of 0.36 .

Respondents also care about the cost of electricity (OUTLAY and outLAY ${ }^{2}$ ). The coefficient of OUTLAY is -0.00339 meaning that each Dollar spent on electricity reduces utility be 0.00339 units. At the median level for outlay, amounting to USD 120 annually, utility is reduced by 0.41 units. This is comparable to the utility gained by solving the waste disposal problem or by having a low frequency of blackouts (both 0.36). The positive coefficients of OUTLAY $^{2}$ and INCOME OUTLAY point to a decreasing marginal utility of income.

Because $44 \%$ of the respondents did not report their income, we added the term INC_MISSG - OUTLAY (see last term in Table 1). The coefficient of this term turns out to be 85,050 times greater than the coefficient of the term INCOME-OUTLAY, indicating that those respondents not reporting income value nuclear risk as though their income was roughly CHF 11,500 greater than the average income of those reporting income (CHF 73,480, see Table 2). By including INC_MISSG - OUTLAY in our regression, we take this effect into account. In addition, we checked whether those respondents not reporting income differ systematically in their valuation of the product attributes from those not reporting income. To this end we added interaction terms between the dummy variable INC_MISSG and the product attributes. Because all these interaction terms were not statistically significant, we conclude that missing observations for income do not systematically distort our findings.

\subsection{Effect of Attitudinal Variables on Willingness to Pay}

Using eqs. (2) and (3), respectively, $M W P_{C}$ and $M W P_{W}$ are evaluated for different values of SEXM and PESS while keeping the remaining variables at the sample median values (see Table 2). The results in Table 2 indicate that women are more concerned about nuclear risks than men (see the negative coefficient of SEXM $\cdot$ COVERAGE in Table 3).

Indeed, pessimistic women are willing to pay an estimated 70 percent more than comparable men for a marginal increase in insurance coverage $\left(M W P_{C}=1.96\right.$ $\mathrm{USD} /$ year compared to $1.13 \mathrm{USD} /$ year) and roughly 45 percent more than men 
for solving the waste disposal problem $\left(M W P_{W}=212 \mathrm{USD} /\right.$ year compared to $147 \mathrm{USD} /$ year). This differential is similar for non-pessimistic women in relative terms, viz. some 75 percent with respect to increased insurance coverage and 55 percent with respect to solving the waste disposal problem.

Table 4. Marginal Willingness to Pay for Increased Coverage $\left(M W P_{C}\right)$ and for Solving the Waste Disposal Problem $\left(M W P_{W}\right)$, Evaluated at Median Distance $(36 \mathrm{~km})$ in USD per Year

\begin{tabular}{lcc}
\hline & Value & s.e. \\
\hline$M W P_{C}{ }^{a}$ & & \\
pessimistic men & 1.13 & 0.47 \\
pessimistic women & 1.96 & 0.51 \\
non-pessimistic men & 1.08 & 0.45 \\
non-pessimistic women & 1.90 & 0.50 \\
\hline$M W P_{W}$ & & \\
pessimistic men & 146.94 & 32.05 \\
pessimistic women & 212.14 & 35.23 \\
non-pessimistic men & 114.74 & 32.21 \\
non-pessimistic women & 179.94 & 34.21 \\
\hline
\end{tabular}

a for a percentage point change, e.g. from 1 to 2 percent of maximum loss.

\subsection{The Effect of Distance on Willingness to Pay}

The results in Table 1 show that DIST - COVERAGE has a negative coefficient, meaning that the marginal utility from additional insurance coverage decreases with distance from the plant. However, DIST · PESS · COVERAGE is positive, significantly reducing the overall effect of distance on marginal utility of insurance coverage. Also, non-pessimistic women ( $\mathrm{SEXM}=0$ and PESS $=0)$ exhibit a strong negative distance gradient whereas pessimistic men show a positive distance gradient for $M W P_{C}$. These findings indicate that SEXM and PESS are able to control for respondents' attitudes.

Section 3. contains several predictions regarding the effects of DIST on the marginal wtp for coverage $\left(M W P_{C}\right)$ and wtp for resolving the waste problem $\left(M W P_{W}\right)$. Specifically, prediction (1) states that $M W P_{C}$ should exhibit an inverted U-shaped relationship with distance from plant to the extent that sorting effects are important. This condition likely is satisfied for pessimistic men. Indeed, Figure 1 shows such a relationship. Up to a distance of roughly $30 \mathrm{~km}$, pessimistic men's marginal willingness to pay for additional insurance coverage is zero 
but increases to about USD 5 per year for those living about $100 \mathrm{~km}$ away from the nuclear power plant. This is a substantial amount. Assuming constant marginal utility of additional insurance coverage, a pessimistic man living at $100 \mathrm{~km}$ distance from the plant is willing to pay up to USD 500 (USD 5 per percentage point) per year for full insurance coverage.

Next, prediction (2) states that controlling for attitudinal variables in the regression makes a difference by identifying the (negative) direct effect of distance from plant on $M W P_{C}$. This means that pessimists ( a positive effect relative to optimists. The coefficient of DIST - PESS - COVERAGE in Table 1 is positive. Also, opponents (opponent $=1$ ) to nuclear energy should exhibit a positive effect as well.Here, the coefficient of DIST · OPP · COV is negative but lacks significance. As argued in Section 3, men are hypothesized to be more strongly sorted than women, causing the sorting effect to become (more) prominent. In fact, a positive coefficient is found for DIST · SEXM $\cdot$ COV.

Because the indicators PESS, OPPONENT and SEXM are designed to capture the sorting effect, the marginal wtp for more comprehensive insurance coverage $\left(M W P_{C}\right)$ should be decreasing in distance for non-pessimistic women not opposed to nuclear energy (PESS $=0$, OPPONENT $=0$, SEXM $=0$ ). Figure 1 shows that non-pessimistic women close to the nuclear plant do exhibit positive wtp for additional coverage amounting to USD 7. However, their marginal willingness to pay drops with distance from plant and becomes indistinguishable from zero for non-pessimistic women living 50 kilometers or more away from the plant.

In contrast, Figure 1 reveals a positive but constant $M W P_{C}$ for pessimistic women. Non-pessimistic men (Figure 1) also exhibit constant but lower $M W P_{C}$ values. In all, hypothesis (2) is largely confirmed.

Turning to the waste problem, hypothesis (3) states that sorting should not make a difference with respect to $M W P_{W}$. Both DIST - NOWASTE and DIST $^{2} \cdot$ NOWASTE fail to attain statistical significance in Table 3. The distance gradients of wtp for solving the waste disposal (and transportation) problem are flat in all cases (not shown). Finally, prediction (4) states that higher income goes along with higher values of both $M W P_{C}$ and $W P T_{W}$. Indeed, the negative partial effect of outLAY is mitigated by a positive one associated with INCOME - OUTLAY. Therefore, the denominator in equations (2) and (3) goes towards zero with increasing income, causing $M W P_{C}$ and $M W P_{W}$ to increase. 
Figure 1. Marginal willingness to pay for increased coverage with respect to distance (measured in $\mathrm{km}$ ) from nuclear power plant, in USD per year. The thin lines show the 95 percent confidence intervals calculated using the Delta method.

(a) Non-pessimistic women

(b) Pessimistic women

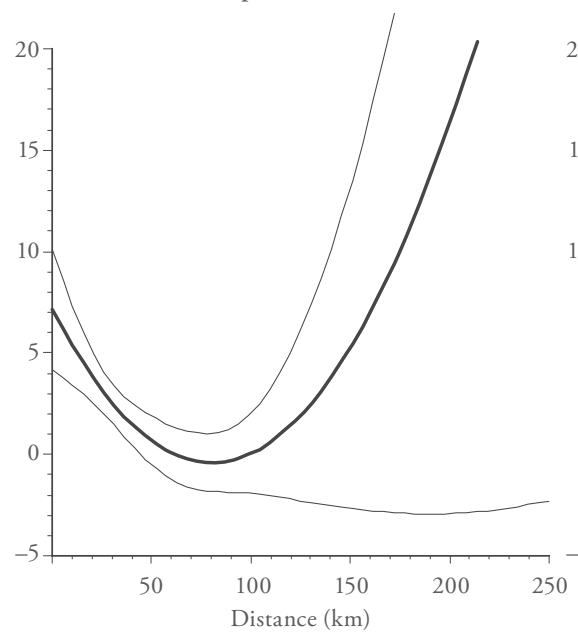

(c) Non-pessimistic men

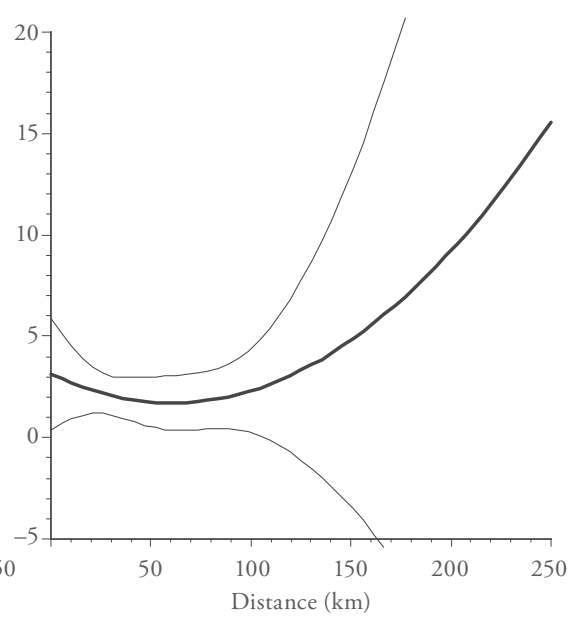

(d) Pessimistic men

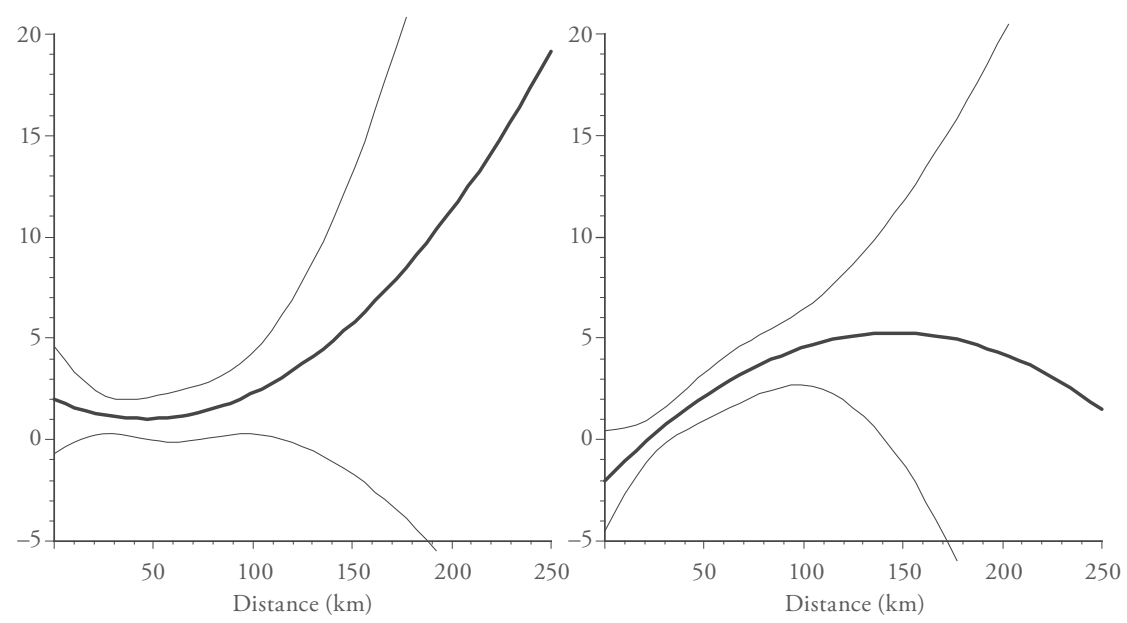




\section{Conclusion}

This article investigates the effect of distance from nuclear power plants on Swiss citizens' marginal willingness to pay for avoiding two particular risks from nuclear power: the risk of an accident at power plants, and the risk associated with nuclear waste disposal. The reduction of the (financial) risk from nuclear accidents was framed as increased insurance coverage against losses caused by accidents at power plants.

In the case of Switzerland, respondents had ample opportunity to choose their residential location according to their preferences regarding nuclear power. If spatial sorting of individuals is indeed important, one would expect to find more strongly concerned people residing at a greater distance from plants, resulting in an inverted U-shaped relationship between marginal willingness to pay for increased insurance coverage $\left(M W P_{C}\right)$ and distance. On the other hand, if spatial sorting is not important, one would expect a negative relationship between $M W P_{C}$ and distance because exposure to the accident risk decreases with distance.

Using data obtained from a discrete choice experiment, respondents distance from nuclear power plants proves to be a significant explanatory variable for $M W P_{C}$. Controlling for attitudinal variables, the distance gradient of $M W P_{C}$ turns out to display the predicted inverted U-shaped profile: Close to the plant (less than $30 \mathrm{~km}$ ), marginal willingness to pay is not statistically different from zero. At greater distance, however, it reaches USD 4 to USD 5 per year for a one percentage point increase in insurance coverage. On the other hand, individuals who did not sort spatially with respect to their nuclear risk preferences show a negative distance gradient: Marginal willingness to pay starts at USD 7 per year for those living close to a nuclear power plant and reaches USD 0 at a distance of $50 \mathrm{~km}$ from the plant.

Because the risk emanating from nuclear waste disposal is hardly affected by the distance between the individual's residential location and nuclear power plants, distance from plant is predicted to have no impact on willingness to pay for a solution to the waste disposal problem. Our analysis confirms this hypothesis as well: Regardless of distance, respondents are willing to pay up to USD 212 per year for having the waste disposal problem solved.

Although the risks considered in this study are rather abstract, the findings from the discrete choice experiment are in accordance with economic intuition to a surprising degree. This encourages the use of discrete choice experiments for measurement of preference with regard to complex goods and services. In particular, discrete choice experiments may provide a valuable basis for policy 
decisions such as phasing out nuclear power. Because respondents must trade off several desirable attributes of electricity such as a low accident risk, a low price, and a high security of supply against each other, this method permits to put a reliable price tag on each attribute. Table 1 , for example, indicates that respondents value security of supply by roughly the same amount as they value a solution to the waste disposal problem. Discrete choice experiments clearly provide more detailed information than surveys that simply ask citizens whether they approve or disapprove a nuclear phase-out.

\section{A. Appendix}

\section{A.1 Example of a Choice Scenario}

Table A1: Example of a Choice Scenario

\begin{tabular}{|c|c|c|}
\hline & Type A power & Type B power \\
\hline Price & $\begin{array}{l}\text { A kilowatt hour costs the same as } \\
\text { today }\end{array}$ & $\begin{array}{l}\text { A kilowatt hour is } 60 \text { percent more } \\
\text { expensive than today }\end{array}$ \\
\hline Blackout & 2 blackouts per year on average & 2 blackouts per year on average \\
\hline Waste & $\begin{array}{l}\text { There are unresolved problems } \\
\text { with waste disposal }\end{array}$ & $\begin{array}{l}\text { There are no unresolved problems } \\
\text { with waste disposal }\end{array}$ \\
\hline Damage & $\begin{array}{l}\text { A large-scale accident can cause } \\
\text { losses up to a maximum of Swiss } \\
\text { francs } 200 \text { bn. (This amounts to } \\
\text { Swiss francs } 70,000 \text { per household } \\
\text { on average) }\end{array}$ & $\begin{array}{l}\text { A large-scale accident can cause } \\
\text { losses up to a maximum of Swiss } \\
\text { francs } 100 \mathrm{mn} \text {. (This amounts to } \\
\text { Swiss francs } 35 \text { per household on } \\
\text { average) }\end{array}$ \\
\hline Insurance coverage & $\begin{array}{l}1 \text { percent of this maximum damage } \\
\text { is covered }\end{array}$ & $\begin{array}{l}100 \text { percent of this maximum } \\
\text { damage is covered }\end{array}$ \\
\hline Your Choice: & $\square$ Choose A & $\square$ Choose B \\
\hline & \multicolumn{2}{|c|}{$\square$ cannot decide } \\
\hline
\end{tabular}




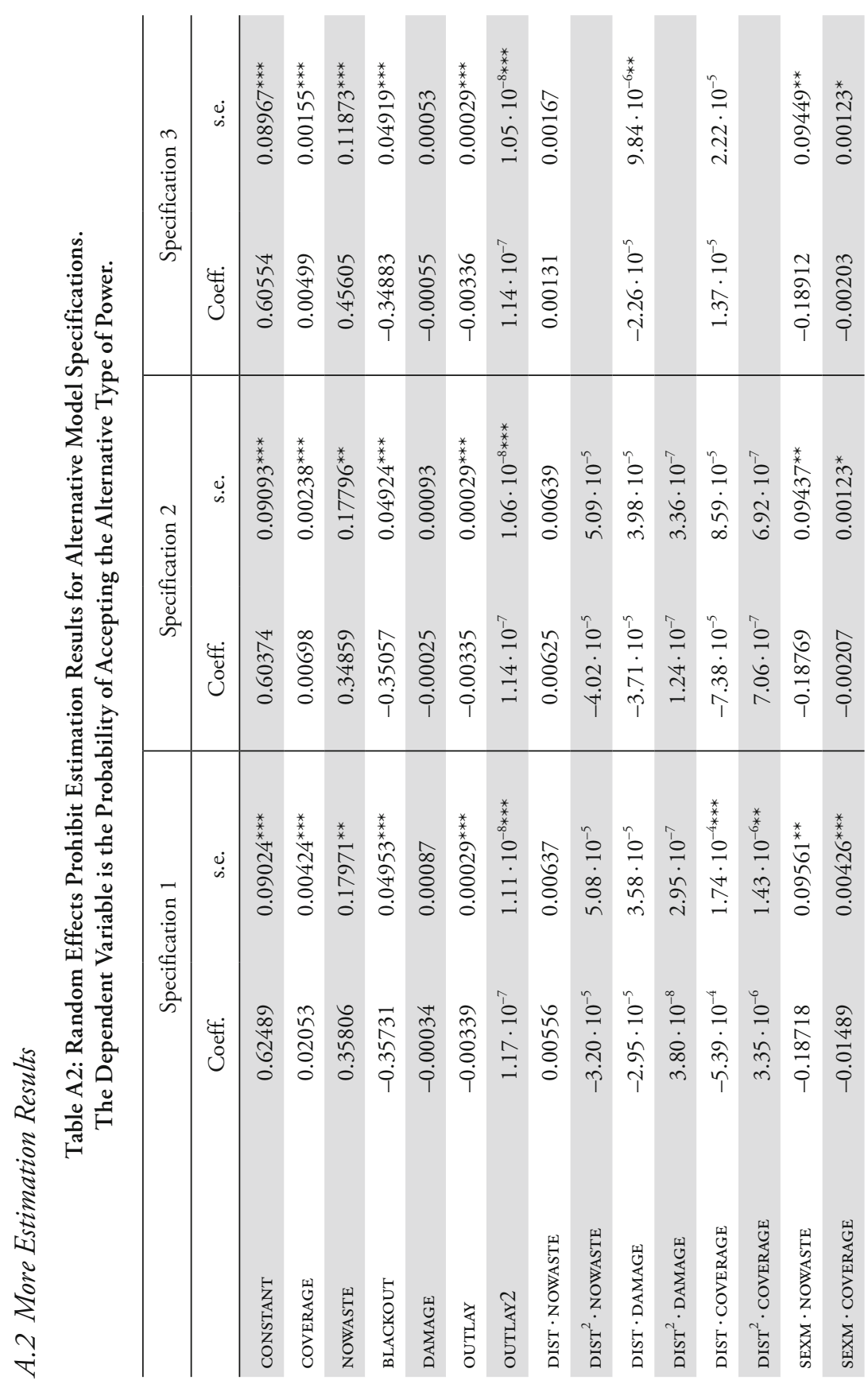




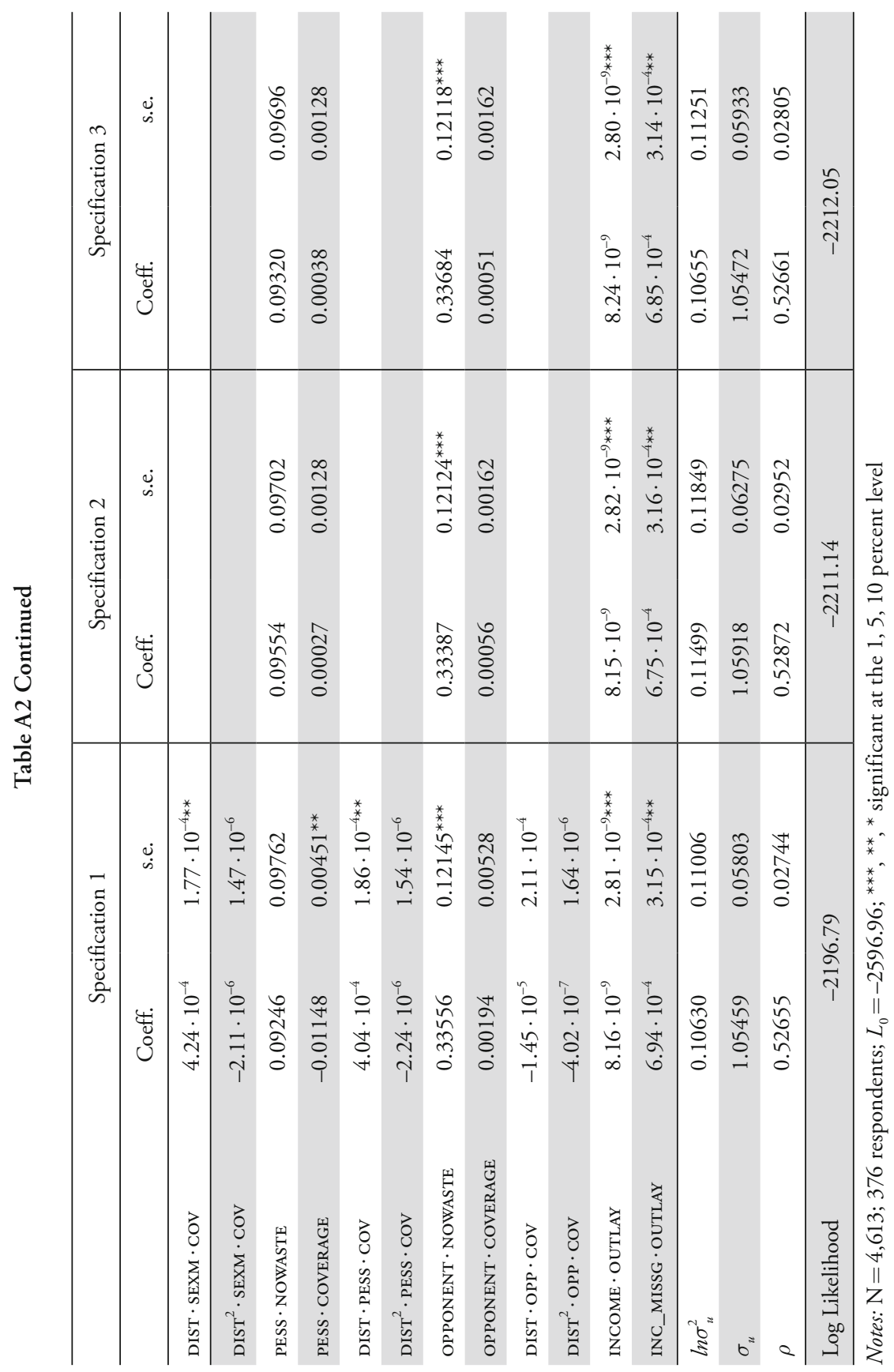




\section{References}

Bishop, Richard C., and Thomas A. Heberlein (1979), "Measuring Values of Extramarket Goods: Are Indirect Measures Biased?", American Journal of Agricultural Economics, 61(5), pp. 926-930.

Clark, David E., and Tim Allison (1999), "Spent Nuclear Fuel and Residential Property Values: The Influence of Proximity, Visual Cues and Public Information", Papers in Regional Science, 78(4), pp. 403-421.

Davis, Lucas W. (2004), "The Effect of Health Risk on Housing Values: Evidence from a Cancer Cluster", American Economic Review, 94(5), pp. 1693-1704.

de Bekker-Grob, Esther W, Mandy Ryan, and Karen Gerard (2010), "Discrete Choice Experiments in Health Economics: A Review of the Literature", Health Economics, 21(2), pp. 145-172.

Diamond, Peter A., and Jerry A. Hausman (1994), "Contingent Valuation: Is Some Number Better than No Number?", The Journal of Economic Perspectives, 8(4), pp. 45-64.

Dionne, Georges, and Louis Eeckhoudt (1985), "Self-Insurance, Self-Protection and Increased Risk Aversion”, Economics Letters, 17(1-2), pp. 39-42.

Ehrlich, Isaac, and Gary S. Becker (1972), "Market Insurance, Self-Insurance, and Self-Protection", The Journal of Political Economy, 80(4), pp. 623-648.

Farber, Stephen (1998), "Undesirable Facilities and Property Values: A Summary of Empirical Studies”, Ecological Economics, 24(1), pp. 1-14.

Folland, Sherman, and Robbin Hough (2000), "Externalities of Nuclear Power Plants: Further Evidence”, Journal of Regional Science, 40(4), pp. 735-753.

Gamble, Hays B., and Roger H. Downing (1982), "Effects of Nuclear Power Plants on Residential Property Values", Journal of Regional Science, 22(4), pp. 457-478.

Gawande, Kishore, and Hank Jenkins-Smith (2001), "Nuclear Waste Transport and Residential Property Values: Estimating the Effects of Perceived Risks", Journal of Environmental Economics and Management, 42(2), pp. 207-233.

Gyrd-Hansen, Dorte, and Ulla Slothuus (2002), "The Citizen's Preferences for Financing Public Health Care: A Danish Survey", International Journal of Health Care Finance and Economics, 2(1), pp. 25-36.

Hanemann, W. Michael (1984), "Welfare Evaluations in Contingent Valuation Experiments with Discrete Responses", American Journal of Agricultural Economics, 66(3), pp. 332-341.

Hardin, R. H., and N. J. A. Sloane (1991-2003), GOSSET: A General-Purpose Program for Designing Experiments, www.research.att.com/ñjas/gosset/. 
Hartog, Joop, Ada Ferrer-i Carbonell, and Nicole Jonker (2002), "Linking Measured Risk Aversion to Individual Characteristics", Kyklos, 55(1), pp. 3-26.

Ida, Takanori, and Toshifumi Kuroda (2006), "Discrete Choice Analysis of Demand for Broadband in Japan", Journal of Regulatory Economics, 29(1), pp. 5-22.

Kelly, Mary, and Anne E. Kleffner (2003), "Optimal Loss Mitigation and Contract Design", The Journal of Risk and Insurance, 70(1), pp. 53-72.

Louviere, Jordan, David Hensher, and Joffre Swait (2000), Stated Choice Methods - Analysis and Applications, Cambridge University Press.

Louviere, Jordan J., David Pihlens, and Richard Carson (2010), "Design of discrete choice experiments: A discussion of issues that matter in future applied research", Journal of Choice Modelling, 4(1), pp. 1-8.

Nelson, Jon (1981), "Three Mile Island and Residential Property Values: Empirical Analysis and Policy Implications", Land Economics, 57(3), pp.363-372.

Nielsen, Jesper B., Dorte Gyrd-Hansen, Ivar Sønbø Kristiansen, and JørGen NeXøe (2003), "Impact of Socio-demographic Factors on Willingness to Pay for the Reduction of a Future Health Risk", Journal of Environmental Planning and Management, 46(1), pp. 39-47.

Riddel, Mary, Christine Dwyer, and W. Douglass Shaw (2003), "Environmental Risk and Uncertainty: Insights from Yucca Mountain", Journal of Regional Science, 43(3), pp. 435-457.

Schneider, Yves, and Peter Zweifel (2004), "How Much Internalization of Nuclear Risk Through Liability Insurance?”, Journal of Risk and Uncertainty, 29(3), pp. 219-240.

Smith, Kerry, and William H. Desvousges (1986), "The Value of Avoiding a LULU: Hazardous Waste Disposal Sites", The Review of Economics and Statistics, 68(2), pp. 293-299.

Telser, Harry, and Peter Zweifel (2002), "Measuring Willingness-To-Pay For Risk Reduction: An Application of Conjoint Analysis", Health Economics, 11(2), pp. 129-139. 


\section{SUMMARY}

How to deal with the risks associated with nuclear energy is a major policy issue. This paper investigates the effect of an individual's distance from nuclear power plants on willingness to pay for increased insurance coverage against nuclear accidents $\left(M W P_{C}\right)$ as well as on willingness to pay for solving the nuclear waste disposal problem $\left(M W P_{W}\right)$. Using data from a discrete choice experiment conducted in Switzerland, we find evidence that $M W P_{C}$ values decrease with distance from plant once attitudes influencing choice of residential location are controlled for. However, distance from plant has no effect on $M W P_{W}$ values. 